\title{
"Interações Arriscadas"1 relações entre arte contemporânea e educação
}

\section{"Risky interactions" relationships between contemporary art and education}

\author{
Angela Maria de Andrade Palhano \\ Mestre em Educação pela Universidade Regional de Blumenau (FURB) - \\ angela.palhano@avantis.edu.br - orcid.org/0000-0003-1128-0178 \\ Sandra Regina Ramalho e Oliveira \\ Doutora em Comunicação e Semiótica pela Pontifícia Universidade Católica de São Paulo (PUC/SP) - \\ ramalho@floripa.com.br - orcid.org/0000-0002-6447-2096
}

\section{Resumo}

Com a intenção de contribuir para as discussões que acontecem nos meios acadêmicos sobre como inserir a arte contemporânea na educação, e para defender a noção de que a arte de hoje é mais próxima do cotidiano, neste texto comentam-se processos artísticos de quatro artistas contemporâneos que usam em sua poética o elemento mais indispensável para a vida: a água. Contextualiza-se a arte na contemporaneidade, inicialmente destacando as mudanças ocorridas nos últimos tempos, inclusive as decorrentes das novas tecnologias. Conclui-se que as atuais políticas públicas para a educação estão na contramão do que a arte oferece, bem como que os/as professores/as podem potencializar o seu fazer através da compreensão da nova lógica.

Palavras-chave: Arte moderna - Séc. XX. Arte - Estudo e ensino. Arte - Temas, motivos. Água - Temas, motivos

\begin{abstract}
With the intention of contributing to the discussions that happen in academic fields about how to insert contemporary art in education, and to defend the notion that the art of today is closer to the day-to-day, in this text are commented the artistic processes of four contemporary artists that use in their poetics the most indispensable element for life: the water. Contemporary art is contextualized, initially highlighting the changes that have occurred in recent times, including those resulting from new technologies. It is concluded that the current public politics for education are in the opposite direction of what art offers, as well as that teachers must understand the new logic in force to take advantage of the potential of current art.
\end{abstract}

Keywords: Art, Modern - 20th century. Art - Study and teaching. Art -Themes, motives. Wather - Themes, motives

Recebido em: 05/03/2020

Aceito em: 10/06/2020

${ }^{1}$ Título de um dos livros do semioticista Eric Landowski. 


\section{NASCENTES}

Algo entre o intangível e a fluidez parece sustentar os discursos artísticos atuais, nos quais a água torna-se matéria e poética. A predileção por materiais fluídos na arte decorre de condições práticas, intenções simbólicas e alegóricas associadas a inconsistências físicas e propriedades químicas. Na arte contemporânea, hibridizam-se outros aspectos e discursos provocados a partir dessa materialidade, no que pode ser o informe, no que escorre, desvia, percorre, flutua, afunda, retém, evapora, molda-se, mistura-se, reflete, flui, refresca, alimenta.

Na perspectiva de estabelecer canais de ligação da educação com as produções dos artistas Raquel Stolf e Helder Martinovsky, buscaram-se trabalhos contemporâneos propostos com água, rio e mar. Para tanto, optou-se por destacar produções de arte, que além das contextualizações desejadas, estabelecem diálogos com o vivido pelas autoras ${ }^{2}$ deste artigo e com o ensino de arte. Dessa maneira, diante de inúmeros exemplos que se poderia trazer, selecionou-se também o trabalho de mais duas artistas, A Gente Rio de Carolina Caycedo e as Formas Fluídas de Amelia Toledo. Da investigação de ambientes e materialidades, ambas propositoras produziram fluxos artísticos que circulam, insinuam, borbulham, explodem e se expandem ao alcance da imaginação.

O objetivo foi abordar aspectos da arte contemporânea que podem ser objeto de estudo na educação, no sentido de contextualizar e instigar o pensamento sobre essa relação e seu potencial disruptivo no que é cotidiano e no ensino de arte. O embasamento teórico foi buscado em Michael Archer (2001), quando o autor apresenta as mudanças ocorridas na arte nos últimos quarenta anos, perpassando, num quadro cronológico, movimentos artísticos e produtores referenciais na relação entre arte e vida contemporânea. Anne Cauquelin (2005) e Michael Rush (2006) relacionam os vínculos artísticos com o desenvolvimento do planeta tecnológico e conectado. Ouvir o mar e sentir as vibrações por ele causadas foram convites de participação para ouvir o silêncio, propostos por diferentes modulações, sobreposições, ressonâncias e assonâncias que abrigam modificações e o fazer artístico de Raquel Stolf $(2011,2017)$. As proposições de Favaretto (2010) auxiliaram a articulação dialógica entre a arte contemporânea e a educação, sobretudo no papel dos/as

\footnotetext{
${ }^{2}$ Angela Maria de Andrade Palhano reside em Florianópolis - litoral catarinense e Sandra Regina Ramalho e Oliveira em Rio do Sul - cidade do Alto Vale, onde se forma o rio Itajaí-Açu.
} 
professores/as diante da superação de práticas pedagógicas de outros tempos e incentivando-os/as a promover uma virada significativa no plano educacional.

As principais ideias discutidas neste artigo referem-se às articulações das proposições artísticas presentes nas discussões da tese que tem por título Acesso à arte contemporânea no Ensino Médio: interações e sentidos, a ser defendida no Programa de Pós-Graduação em Artes Visuais (PPGAV), na Universidade do Estado de Santa Catarina (UDESC), na linha de pesquisa Ensino das Artes Visuais, no ano de 2020.

\section{A ARTE E A CONTEMPORANEIDADE}

O grau de complexidade da arte contemporânea decorre da sua estreita relação com a vida cotidiana, fundada nas descaracterizações do mundo atual, as quais carregam conjuntamente referências de outros tempos e espaços. O público, originário de uma tradição acerca da arte que a mantinha no patamar do inacessível, reiterado por molduras douradas e isolada em templos faraônicos, com sua produção tida como decorrente da genialidade dos portadores de um dom, paradoxalmente, quando utiliza o banal e se mistura no cotidiano, a arte contemporânea causa estranhamento aos destinatários, quebra paradigmas e desequilibra os conceitos do senso comum.

Num panorama geral, questões sociopolíticas surgidas na segunda metade do século XX, como a agilidade nos meios de comunicação, difusão e trocas culturais, globalização, mercado financeiro e expansão, ampliação de conceitos de espaço, lugar, identidades e diferenças, desdobraram-se em outros entendimentos e sentimentos, reinventando contextos, caraterísticas e novas maneiras de viver. Da imaginação à realidade, o mundo expandiu-se pela comunicação cada vez mais acrescida por avanços tecnológicos, integrando-se na rotina diária dos sujeitos, citando-se apenas a internet e as redes sociais. Intercâmbios culturais, avanços científicos e interfaces entre vários segmentos ultrapassam fronteiras e reduzem distâncias, benefícios esses entranhados no sistema da vida contemporânea. Por outro lado, desenvolveram-se os efeitos da era da comunicação, gerados a partir da competição determinada por uma espécie de invasão tecnológica. Cauquelin (2005), destacou os "efetuadores", noções que dão suporte ao sistema comunicacional, entre eles, a rede, a autonomia, a redundância, a prevalência sobre o conteúdo e a construção da realidade em segundo grau. De acordo com a autora, a noção de rede se refere ao sistema comunicativo, permitindo o acesso a partir de seus aparelhos e propriedades, ou seja, insere-se na ordem da 
conexão constante, gerando vínculos gradativamente necessários e ainda uma noção mais subjetiva, resultando da ausência de autoria, pois o conteúdo não é de um sujeito, mas da rede.

Isso também afeta a arte, pois o efeito da autonomia se dá na extensão, circularidade e repetitividade da rede, que faz com que a sua atuação seja eficiente a tal ponto que os sujeitos se envolvam, cada vez, por mais tempo na malha comunicacional, sendo inundados por imagens, as mais diversas, as quais competem com a arte. Cauquelin (2005, p. 63), comenta ainda que a construção dessa realidade em segundo grau continua sendo oportunizada por uma linguagem específica onde "se estruturam não somente os grupos humanos, mas, ainda, a apreensão das realidades exteriores, a visão do mundo, sua percepção e sua ordenação", questões fluentes para abordagens na educação. Nesse aspecto, a linguagem midiatizada se configura outra realidade virtual, que não aquela imaginada, mas a que é artificialmente construída e que passa a orientar os comportamentos, valores e subjetividades, por isso refere-se à realidade cibernética.

Se o mundo se tornou um mutante comunicacional, a arte cindiu-se nele, resultando na “desconcertante profusão de estilos, formas, práticas e programas" (ARCHER, 2001, prefácio). Archer situou as produções incomuns que despontavam no mundo da arte, como performances, happenings, apropriações de objetos, pinturas, esculturas e desenhos em campo expandido, experimentações diversas que se proliferavam, em boa parte, provocados pelas ideias de Marcel Duchamp (1887-1968) que, extrapolando padrões artísticos com o uso de objetos prontos, chegou ao conceito, o que consistiu em uma mudança radical, que interferiu diretamente no pensamento sobre a arte no final do século XX.

Como outro dos marcos da arte contemporânea, Rush (2006, p.18) destacou o Fluxus, um "movimento internacional de artistas, escritores, cineastas e músicos sob a liderança de George Maciunas (1931-78)", que integrou ocorrências casuais e os participantes em suas interpretações, bem como os roteiros das composições de John Cage (1912-92), que exigiam atenção apenas para um detalhe destituindo o contexto orquestral ou performático para seguir instruções mínimas. Esses movimentos promoveram uma nova relação do público com a arte, face às alterações que também aconteciam mutuamente. Reagindo contra a rigidez formal e experimentando a liberdade do improviso, propositores e participantes permitiam-se vivenciar o processo e a surpresa, pois tudo poderia acontecer no momento em que acontecia, assim esses elementos passaram a fazer parte da forma final da arte. 
Outros experimentos se desenvolveram então, articulando a associação entre arte, tecnologia e meios de comunicação. Seguindo a estética minimalista, os filmes ${ }^{3}$ tornaram-se manifestações artísticas ao romperem com a lógica da comunicação de massa em grande escala, bem como com as produções sofisticadas para se dedicarem ao detalhe. Conforme Rush (2006, p.19):

\begin{abstract}
O filme não era nada mais do que aproximadamente 1000 pés de película de $16 \mathrm{~mm}$, em branco, projetados, sem processamento, sobre a tela, durante 30 minutos. Ao deixar o filme apenas com o mínimo essencial (a película, em si), a projeção sem imagens de Paik tornouse o exemplo minimalista para todos os Fluxfilmes que se seguiram.
\end{abstract}

Sem imagens ou sons, a projeção de Nam June Paik (1932-2006) subverteu novamente a noção do espectador, eliminando as manipulações usuais da mídia comercial e da indústria do entretenimento, deixando uma tela em branco para livres associações do observador.

Retomando o início das transformações da arte no contexto do século XX, Duchamp tornouse fonte de provocação, encorajamento e influência diante de prodigiosa produção. Das suas investigações, desdobraram-se conceitos, estéticas e relações, motivando diversos experimentos e questionamentos sobre a arte e o mundo. Do objeto à ideia, do suporte ao campo expandido, do comercial ao essencial, do tradicional às tecnologias, do espectador ao participante, todos são rompimentos, atravessamentos, transposições de pensamentos e sentidos da arte contemporânea que, no mínimo, forçou a pergunta o que é arte?, até seu nível mais profundo (RUSH, 2006).

\title{
3 POÉTICAS LÍQUIDAS
}

Além de sua condição vital, o uso da água possibilitou o desenvolvimento de saberes científicos, práticos e simbólicos desencadeando processos culturais, sociais, econômicos, políticos e tecnológicos. Por outro lado, a exploração excessiva, a falta de cuidados ambientais, as disputas territoriais e todo tipo de ganância humana, vêm afastando a percepção da água como recurso natural, chegando à escassez em alguns lugares. Não é somente uma questão de localização geográfica como nas regiões áridas ou de abastecimento com grande demanda nas metrópoles que

\footnotetext{
${ }^{3}$ Os Fuxfilmes, como são denominados, compreendem aproximadamente quarenta filmes de curta metragem criados por diversos artistas (poucos cineastas) associados ao Fluxus. Zen for Film [Zen para filme] (1962-64) de Nam June Paik, um Fluxfilme prototípico, foi apresentado em Fluxhall (o apartamento de Maciuna em Canal Street, Nova Yớk). Efetivamente uma instalação dos primeiros tempos (um quadro vivo consistindo em uma tela caseira de cinema, um piano vertical e um contrabaixo), o filme de Paik deu as costas a todo o mecanismo de produção de filmes em grande escala (RUSH, 2006, p.19).
} 
causam limitações de disponibilidade de água, indispensável para todas as espécies vivas, pois a poluição por envenenamento e depósito de rejeitos nos rios e mares, em pequenas e grandes proporções, são noticiadas quase que diariamente.

Evaporar, moldar, fluir são conceitos trazidos pela arte contemporânea em diversos processos e concepções, sugerindo presenças em estado de suspensão, de transitoriedade, de vazios, de inconsistências entre outras. O interesse pelo informe antecipado, por exemplo, nas pinturas de William Turner e Caspar David Friedrich, retratam interligações substanciais entre a poética artística e as metáforas líquidas. $\mathrm{Na}$ arte atual, os interesses sobre processos fenomenológicos, sensações metafísicas e psicológicas propostas pela fluidez líquida, aludem à efemeridade da arte e da vida, do qual algumas produções aqui referenciadas exemplificam.

Podem-se canalizar assuntos sobre a água, o rio e o mar por diversas abordagens tanto na atualidade quanto nos primórdios da história natural, perpassando âmbitos da vida prática e no plano simbólico, relações essas também abordadas na história da arte. Assim, os termos afundar, reter e fluir interligam-se com a água nos discursos poéticos de rio e mar, a partir dos livres desdobramentos e associações que emergem das proposições artísticas A Gente Rio de Carolina Caycedo, RIVER FILM de Helder Martinosvky, Glu-Glu de Amélia Toledo e Mar paradoxo de Raquel Stolf.

A experiência sensorial e participativa também é destacada nas produções artísticas cuja água e toda sua potência vital são revisitadas. Nesse sentido, novas fontes vertem para expandir as relações entre arte, espaço e público pois, para além das [im]possíveis [des]caracterizações da arte contemporânea, vivencia-se um momento de ressignificação de si mesma e de problematização da vida cotidiana; por vezes irônico, lúdico, agressivo, leviano, banal e/ou encantador. Numa relação de convite ao movimento, impulsionados pelas corredeiras dos rios e devaneios do mar, as produções de Caycedo, Martinovsky, Toledo e Stolf proporcionam inúmeras possibilidades e conexões quando sentidas e refletidas em seus contextos locais, investigativos, processuais e nos desdobramentos provocados em outras realidades.

No entorno dos rios, Carolina Caycedo ${ }^{4}$ registrou realidades através de desenhos, fotografias e objetos. A Gente Rio é um desdobramento da pesquisa de campo Be Dammed (Barrado Seja), iniciada em 2012, no qual ela documenta os impactos causados pela economia extrativista e

${ }^{4}$ 1978, Londres, Reino Unido. Vive em La Jagua, Colômbia e Los Angeles, EUA (Catálogo da 32a Bienal de São Paulo, 2016). 
privatização das águas. Para a 32ạ. Bienal de São Paulo (2016), a pesquisadora-propositora deslocouse para as margens das Usinas Hidrelétricas de Itaipu, Belo Monte no rio Xingu e a represa de Bento Rodrigues $^{5}$, locais percorridos para discutir as Incertezas Vivas.

\begin{abstract}
De volta à exposição, munida de imagens de satélite, documentos e desenhos, discute o impacto ambiental monumental dessas obras em seu entorno. Os depoimentos, relatos afetivos e objetos, como redes de pesca trazidos pela artista, apontam conhecimentos acumulados das comunidades com as quais ela trabalha, que, como um corpo coletivo, resistem aos apagamentos impostos por esses projetos de desenvolvimento (ZUKER, 2016, p. 116).
\end{abstract}

Caycedo buscou imagens ribeiras, expandindo-as para diálogos sobre pertencimento, resistência e descaso, pois segundo Zuker (2016), na Itaipu a expropriação de terras deflagrou o Movimento dos Trabalhadores Rurais sem Terra; na Belo Monte, encontram-se vários problemas de irregularidades fiscais e conflitos com indígenas e, na represa Bento Rodrigues, cerca de quatrocentas famílias aguardam as decisões judiciais para recomeçar o que antes era uma comunidade. Nessas realidades nacionais, a propositora interpelou problemas sócio geográficos, demonstrando em desenhos e narrativas um cruzamento entre as cosmologias dos que tinham o rio como parte estruturante do viver e os impactos causados pelo extrativismo ambiental, conforme destacado nas figuras 1 e 2 da instalação A Gente Rio.

No contexto das incertezas vivas, a arte contemporânea opera fora dos sistemas padrão, escalas e normas, modelos e medidas, porque ela se vale da desordem das coisas e do ambiente. Mas talvez o mais importante: a arte pode fazer isso porque une o pensar e o fazer, a reflexão e a ação buscando ressignificar um lugar-entre esses polos de oposição. $O$ incerto situa-se na delicadeza de cada margem, sendo que Caycedo documentou o deslocamento em desenho e escrita sinuosa, coloriu as investigações de pertencimento e deu forma ao apagamento, com os relatos, afetos e objetos das comunidades que sofrem diante de projetos desenvolvimentistas.

\footnotetext{
${ }^{5}$ Aquela que rompeu levando os rejeitos da mineradora Samarco (Mariana- MG) causando um desastre ambiental sem precedente em 2015. Atualmente, ficou esquecida diante da tragédia de Brumadinho em fevereiro de 2019. 
Fig. 1 - Carolina Caycedo, detalhe da Instalação A Gente Rio. Marcador e tinta sobre papel Canson, 2016.

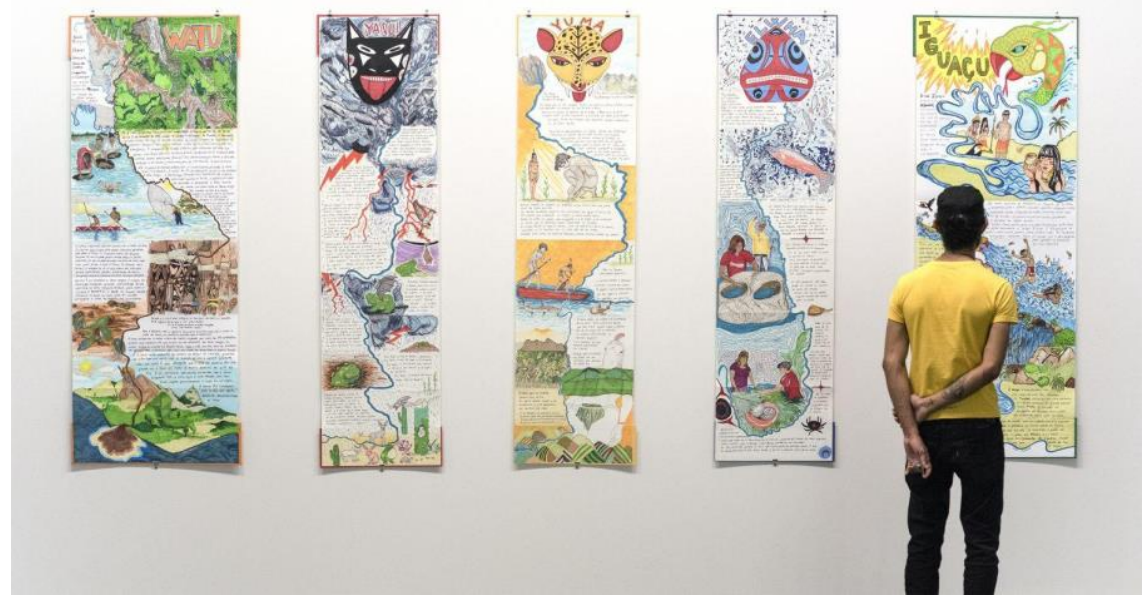

Fonte: http://carolinacaycedo.com/river-books-libros-rio/

Fig. 2 - Carolina Caycedo, detalhe da Instalação A Gente Rio. Marcador e tinta sobre papel Canson, 2016.

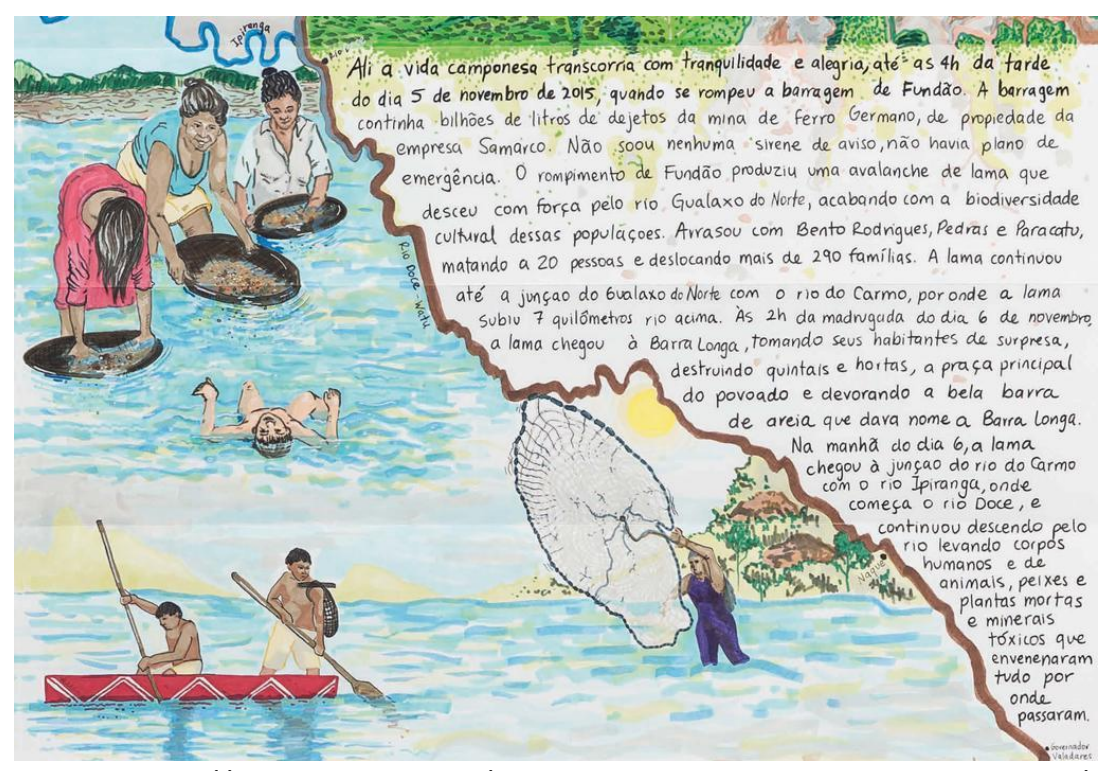

Fonte: https://docplayer.com.br/56895212-A-fome-como-professora.html/

\section{Raquel Stolf (2017, p. 108) comentou em seu artigo Sob/Sobre Notas-Desenhos de Escuta que}

o ato de desenhar tem algo a ver com o perceber, tentar pensar e/ou produzir uma vibração alheia no ar. Desenho-escrevo quando alguma coisa parece estar suspensa e quaseapreendida, quando algo pende e ao mesmo tempo, pausa. Nem que seja por um instante. 
A articulação entre o desenho e a palavra, ou melhor, o "desenho como anotação de escuta" (STOLF, 2017, p. 108), suscita algumas margens que podem ser exploradas no acesso à arte contemporânea e seu ensino, entre o inaudito e o esboçado, a própria escuta e a do outro, a vivência junto ao outro, observando-se por alguns instantes nas oscilações de um participante-leitor-ouvinte.

O trabalho de Caycedo em relação ao deslocamento margeando os rios, tem similaridade à expedição que Helder Martinovsky realizou filmando as nascentes dos rios Tijucas e Itajaí-Açú, situadas na divisa entre os municípios catarinenses de Rancho Queimado e Alfredo Wagner; no seu trajeto pelo rio percorreu doze municípios catarinenses até foz na cidade de Itajaí, resultando na produção RIVER FILM cíclico perpétuo (2013-2016). O filme é movediço, sinuoso, deslizante, orgânico e, transpassando lentamente, pressupõe a disponibilidade de um tempo a mais de visualidade e escuta para aproveitar o seu percurso. Presenciam-se margens que se compõem na união da água com seus borbulhares, redemoinhos e ondulações, com os entornos em vegetações, pedras, barrancos e pontes. RIVER FILM é uma paisagem que emana da manifestação da luz que é fluída e retida, por isso é cíclica e perpétua, mas também é agenciamento de tempo e lugar, podendo recuar instantes vividos tempos atrás, situado num lugar que suspende o natural e o cultural. "Seria o anúncio de um início ou do fim do tempo?" (ZIMMER, 2016, p. 3).

Enquanto Caycedo registra apagamentos e retenções de margens vivas e incertas com a estética de painéis escritos e ilustrados com cores vibrantes, como quem deseja estabelecer um vínculo afetivo e dividir a intimidade de uma realidade trágica, Martinovsky se deteve na captura do movimento das águas, conduzindo o olhar para o entorno do rio, mostrando conjuntamente a superfície da água e a sua travessia. São entrecruzamentos que se multiplicam nas paisagens de rios, além de simbioses por vezes esquecidas e que podem ser rememoradas na construção de sentidos estando em contato com essas proposições. O sensível emana no estar presente, no sentir-se parte do proposto, na ação investigativa, no desenho, nas margens, na luz, no som, sentindo e percebendo materialidades, plasticidades e sonoridades em imagens que tentam reter as formas imprevistas que assumem (STOLF, 2017).

Mesmo diante dos avançados estágios de controle da imagem na arte digital, alguns recursos técnicos do início da videoarte continuam interessando, como é o caso de Martinovksy, que 
configurou a água em estado de rio com filme $16 \mathrm{~mm}^{6}$ em tela grande e o entorno com a super- $8^{7}$ em tela pequena. O formato inicial das gravações foi transportado para exibição em vídeo digital e as imagens acompanhadas por peça sonora em contrabaixo acústico, ensejam efeitos de sentido de mistério. Nos limiares da água em película, vão se formando desenhos no movimento, de onde surgem emaranhados de linhas, oscilações brilhantes entre pontos claros-escuros e experiências de cores em tons acinzentados e sépia.

Os filmes de Martinovsky trazem duas versões de rios, que nascem no mesmo lugar e se dividem, sendo eles mesmos e eles por onde passam, nessa perspectiva, Radunz $(2017$, p. 1) visualiza nas filmagens dos rios a poética da fantasmagoria:

dois rios de dentro, rios de sagas intestinas, correndo alheios/parelhos de 16 em 16 milímetros, em super-8, a oriente, correndo por dentro das velocidades, na sangradura das distâncias, mas lentamente, carregados do que lhes é alheio: folhas: tintas: talos: muros de arrimo; estrumes: bagres: todas as matérias mínimas da imprevisão subaquática; todas as predições dos calendários: toda previsão de marés altas segundo suas próprias réguas maremétricas, mas mira!, tudo isso ainda não é pedra, nada aqui, na correnteza, é penedia, porque o rio só se mantém pelo que não leva-se, porque o rio é fantasmagoria do que é fluência, fantasma de saliva, fantasma-lágrima, como documentar o que não há?

A fantasmagoria do rio está presente em seu contexto de ser o que é. As produções de arte deixam transparecer as marcas de seu processo em traços mínimos diluídos ou em formas mais explícitas. Em seus diferentes contextos, o rio pode ser um mero fluxo de partículas sem nome; porém, na fantasmagoria do rio trazida por Martinovsky ou no barrado seja de Caycedo, ele pode ser cosmologia, imprevisão e caos no vivido de comunidades ribeiras.

Nas imagens a seguir estão retidas duas partes de RIVER FILM: a primeira, dos pontos brilhantes e fluídos de um momento na travessia; e a segunda, o desembocar na foz, finalizando um percurso.

\footnotetext{
"Duração: 16'26".

7 Duração: 11'27".
} 
Fig. 3 - Helder Martinovsky, still de RIVER FILM - cíclico perpétuo, 2013-2016.

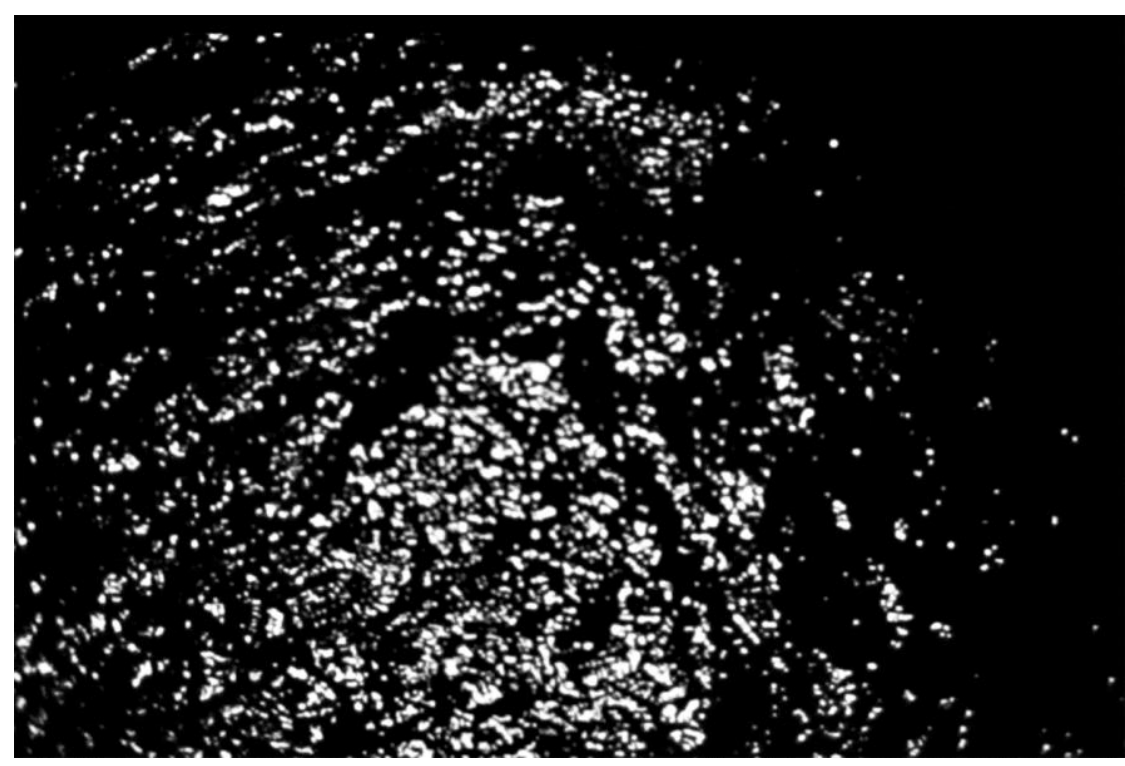

Fonte: Material cedido por Raquel Stolf e Martinovsky.

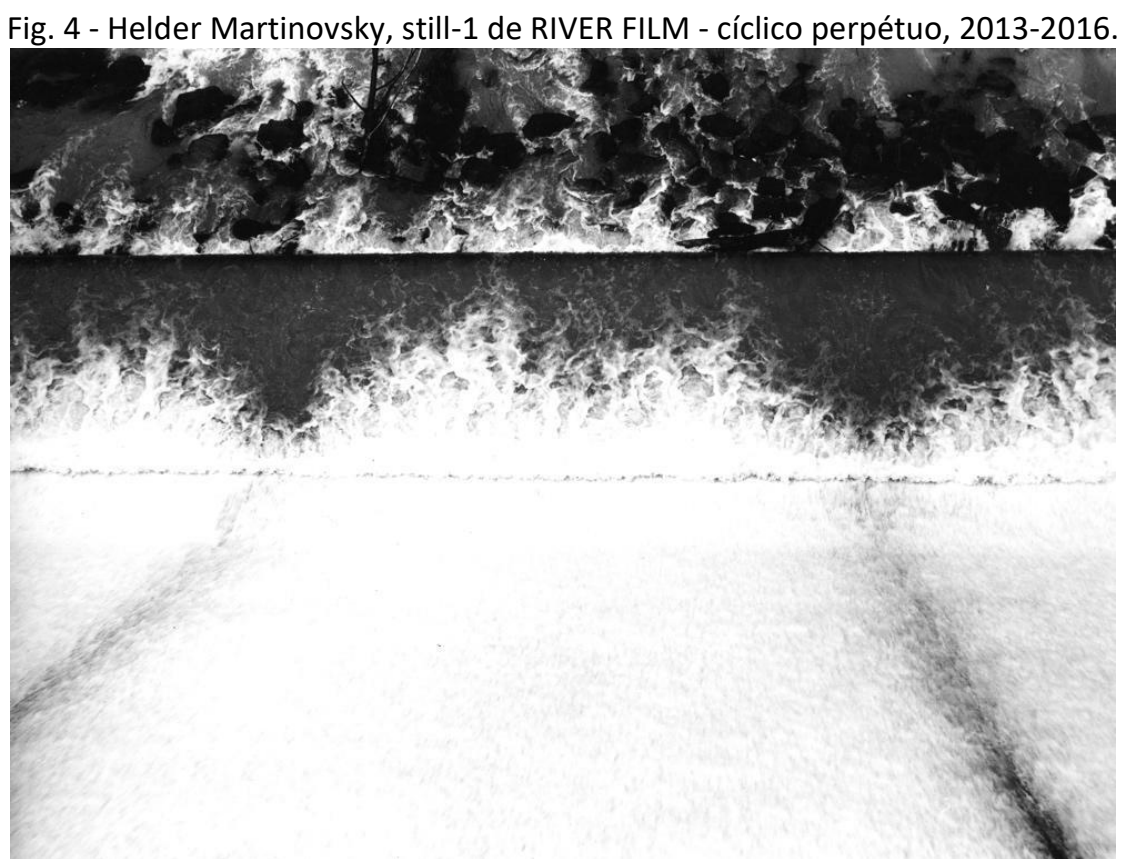

Fonte: Material cedido por Raquel Stolf e Martinovsky.

Amélia Toledo (1926-2017) interessou-se pela água e pelas matérias a ela associadas, como pedras, conchas, cracas e corais, organizando, produzindo e colecionando a série Frutos do Mar, cujo processo partiu da seleção dos materiais de origem marinha e da submersão de peças em resina e vidro nesse ambiente, realizados entre os anos de 1974 a 1982. Algumas de suas produções, como 
as Formas Fluídas, reúnem aspectos potenciais da água como presença na arte, utilizando-se dos artifícios da transparência, da leveza, da fluidez e do movimento, como convites para interagir e sentir. O emblemático Glu-Glu (1968) é um exemplo dessa organicidade, consistindo em uma espécie de ampulheta de vidro contendo água espumante, conforme o transcrito:

arredondada, feminina, ela tem a parte de cima menor que a parte de baixo, o que já aponta para uma contagem de tempo tão imprecisa e mutável quanto a água com espuma abrigada em seu interior. Manipular o Glu-Glu - ter a possibilidade de sacudi-lo ou gira-lo no próprio eixo- é fazer com a água espumante que repousa no receptáculo maior da parte de baixo da peça crie bolhas de sabão que viajam até a parte de cima. É uma escultura evanescente e efêmera, movida pela sinestesia de pelo menos três sentidos: visão, tato e audição, esta última acionada pela sutileza do marulho da espuma e das bolhas explodindo contra a parede de vidro (NAME; COSTA, p. 17, 2015).

Não somente os sentidos físicos parecem ser estimulados na relação de participação com as produções artísticas de Amelia Toledo, mas podem-se inserir aí outros efeitos subjacentes ao modo de presença de sua poética, nos contextos intersubjetivo, interativo e sentido. Se através das imagens das suas obras emerge um desejo latente de tornar-se um corpo-a-corpo envolvido do aqui-agora que impulsiona o contato, a relação, a brincadeira, o reflexo, a reação, enfim as interações, imaginase a intensidade disso tudo e as apreensões vividas no acesso às produções mesmas.

Glu-Glu se deixa mostrar em seu todo, permitindo livres associações entre afundar, reter ou fluir com um fundo que é antes de tudo movediço, tal qual um fundo de mar ou de rio com seus universos túrbidos e imprecisos, ora agitados, ora tranquilos. Por um outro lado, chama a atenção estabelecendo uma relação delicadamente tratada por Raquel Stolf, em assonâncias de silêncio ${ }^{8}$.

8

Publicação sonora assonâncias de silêncios [coleção] (2007-2010). "Coletânea de silêncios gravados em diferentes contextos, agrupados num CD de áudio, juntamente com material impresso, reunindo cinco espécies de silêncibs: silêncios preparados; silêncios acompanhados; silêncios com falhas; silêncios empilhados; fundo do mar sob ruído de fundo" (STOLF, 2017, p.10). 
Figura 5 - Amelia Toledo, Glu-Glu, vidro soprado, espuma e água, 30 cm x 18 cm, 1968/2018.

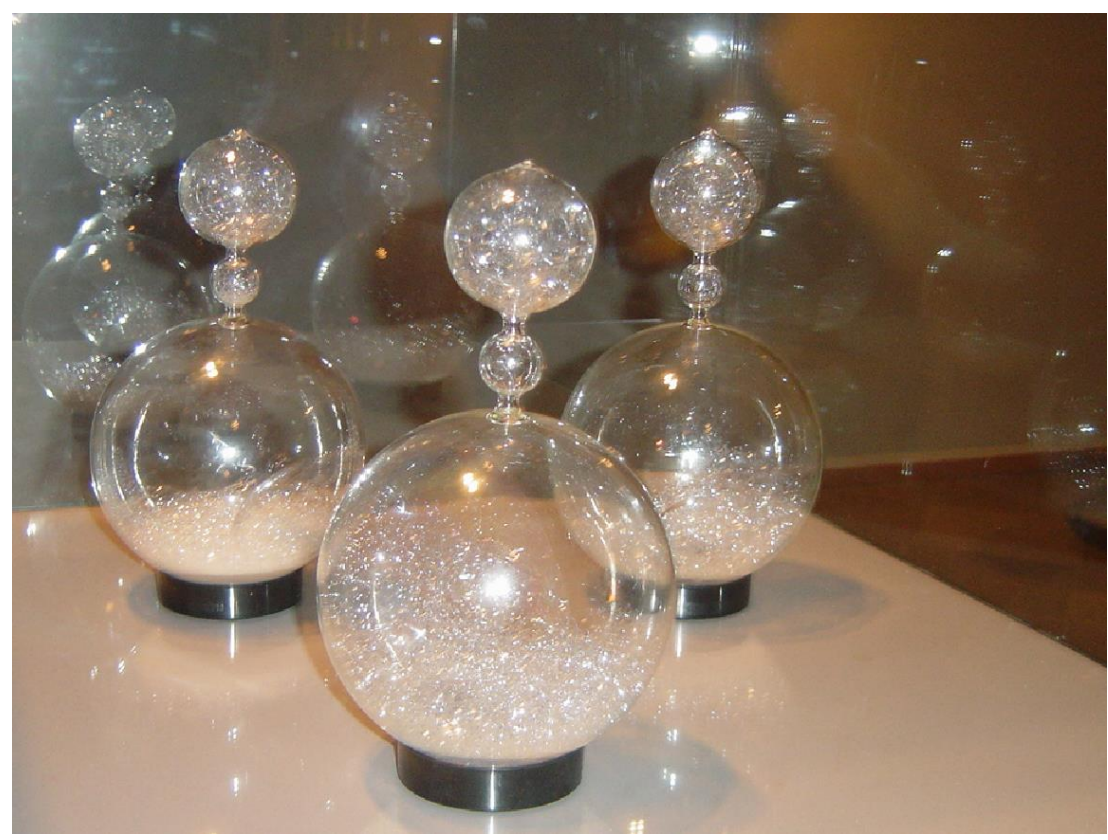

Fonte: Compilação das autoras ${ }^{9}$.

Name e Costa (2015) comentaram sobre a sutileza do marulho das bolhas de espuma explodindo no vidro, e isso soa com as proposições das camadas de silêncio investigadas por Raquel Stolf, que passou a interessar-se pelas tipologias, camadas e texturas de silêncios seguindo a premissa "o silêncio não existe" de John Cage (1978) (STOLF, 2017, p. 111). O conceito de assonância propõe "pensar num silêncio que ressoa no outro, no contexto sonoro que ressoa na escuta e viceversa, desencadeando um processo de reenvio, que solicita uma escuta porosa, uma escutatravessia, permeável, uma escuta esburacada" (STOLF, 2011, p. 207). Como nomear assonâncias espumantes e borbulhantes que estouram voluntariamente? "Como ouvir, escutar e compor/decompor silêncios?" (STOLF, 2011, p. 207). A transparência seria uma forma de silêncio da visualidade?

A vivência em relação com o mar, na cidade do Rio de Janeiro, possibilitou a Amélia Toledo investigar diversas formas plásticas e discursos intuitivos com a água. Somado a isto, as relações pertinentes à própria linguagem da escultura, seja o dentro/fora, cheio/vazio ou espaço/tempo, conduziram-na a experimentações em menor escala, observadas em outras produções, como por

\footnotetext{
${ }^{9}$ Fotografia de Glu-Glu por Angela Maria de Andrade Palhano, Sandra Regina Ramalho e Oliveira na exposição Entre, a obra está aberta de Amelia Toledo, no Museu de Arte de Santa Catarina/MASC (2018). 
exemplo: Bolas-Bolhas (1968), esferas transparentes preenchidas com espuma de sabão, e em maior dimensão as Sete Ondas (1995), escultura em aço inox exposta no Parque Ibirapuera em São Paulo.

A investigação Mar Paradoxo de Raquel Stolf foi proposta por escutas, leituras, instalações, desenhos, anotações e vídeos de silêncio, registrados em material impresso e dois CDs de áudio. Nada convencional com o fazer artístico, o processo se amparou em conhecimentos técnicos como o manuseio de uma câmera digital subaquática, edições das gravações, disposições entre imagens e sons. O material sonoro é composto de cem fundos de mar gravados ao redor da ilha de Santa Catarina, numa profundidade máxima de 14 metros. Mar Paradoxo é um "desdobramento do projeto Assonâncias de silêncios (2007) e do trabalho Fundo do mar sob ruído de fundo (2010), que integra o processo de colecionar, escrever e gravar silêncios de fundos do mar" (STOLF, 2017, p.3).

Os registros gráficos que acompanham Mar Paradoxo fazem pensar na escrita como uma prática artística intertextual, contaminada e disseminada por diferentes modos e campos da linguagem. Trata-se de uma escrita como som e de um som como escrita, promovendo outras possibilidades narrativas, visuais e sonoras. Na trajetória de Stolf (2011, p. 55), "os processos de escrever e construir proposições artísticas são intersectados, entretecidos, amalgamados" Sonoridades, desenhos e escritas complementam-se e segundo sua tese:

a prática da escrita tanto catalisa e desencadeia o processo de minhas proposições, como constitui um método de desdobramento de uma coisa em outra. Uma proposição pode se desdobrar em versões a partir da escrita de títulos e de anotações do processo. Versões que constituem variações de projetos gráficos e sonoros, de formatos, materiais e meios (como a impressão off-set, a editoração/diagramação eletrônica, a gravação e edição de áudio e vídeo digitais, entre outras possibilidades), de conceitos e de "formas de apresentação" ${ }^{10}$ (STOLF, 2011, p. 55-56).

É a dinâmica do vejo/ouço, conforme escreveu Zimmer (2016), onde a escrita/som dialoga com o mundo, extrapolando o verbal e juntando-se à arte em registros do silêncio. Esse é um processo de sentido, onde Stolf articula o in (visível) e o in(dizível) fluidamente, numa oscilação que decorre, escorre do entre-lugar, da confluência rítmica e silenciosa desses fluxos. Assim, não é uma questão de escolha entre um ou outro, mas de pensar sobre alternâncias, outras margens, outras

\footnotetext{
${ }^{10}$ Aspas no original. A autora faz referência à Hélio Fervenza que "desenvolve importantes reflexões em seu texto Formas da Apresentação: da exposição à autoapresentação como arte" (STOLF, 2011, p. 56). O texto de Fervenza está disponível em: https://docplayer.com.br/1659525-Revista-palindromo-2-fervenza-helio.html/. Acesso em: 07 set. 2019. 
possiblidades, porque "o sentido não é nunca apenas um dos dois termos de uma dualidade que opõe as coisas e as sentenças verbais. Ele ocorre entre, no meio, constituindo a articulação de diferenças e/ou ressonâncias" (STOLF, 2011, p.57). Isto também pode se relacionar às produções de Caycedo, no que diz respeito ao limiar entre-margens do que é vivido e do que é idealizado.

Uma das produções em registros gráficos são os cartões notas-desenhos de escuta, onde se observa a conexão existente entre a parte sonora e o seu aspecto visual, mesclados numa complexa partitura envolvida por palavras, símbolos gráficos e linhas, conforme a figura que segue. Esses trabalhos são disponibilizados aos visitantes, que decidem quais e quantos cartões desejam levar consigo. Isso interfere diretamente num desmembramento ou desdobramento, como Stolf gosta de se referir, agregando a ideia de movimentos de aproximação e apropriação na ótica do visitante, e de distanciamento ou deslocamento da produção e desvinculação do seu meio, que também pode ser compreendido como um campo expandido, conforme o indicado nas imagens seguintes.

Fig. 8 - Raquel Stolf, [notas-desenhos de escuta] Mar Paradoxo, 2009-2010.

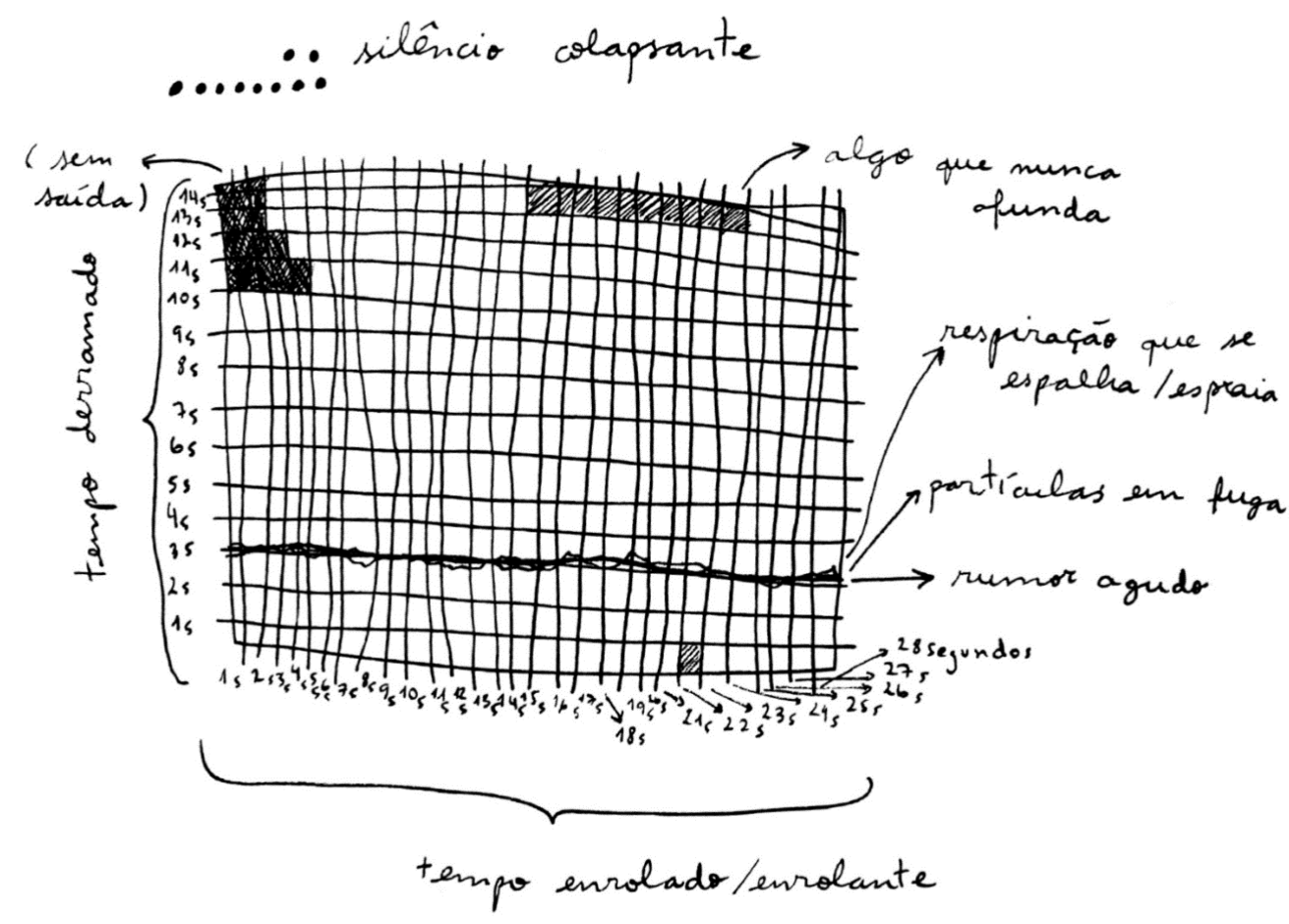

Fonte: Material cedido por Raquel Stolf. 


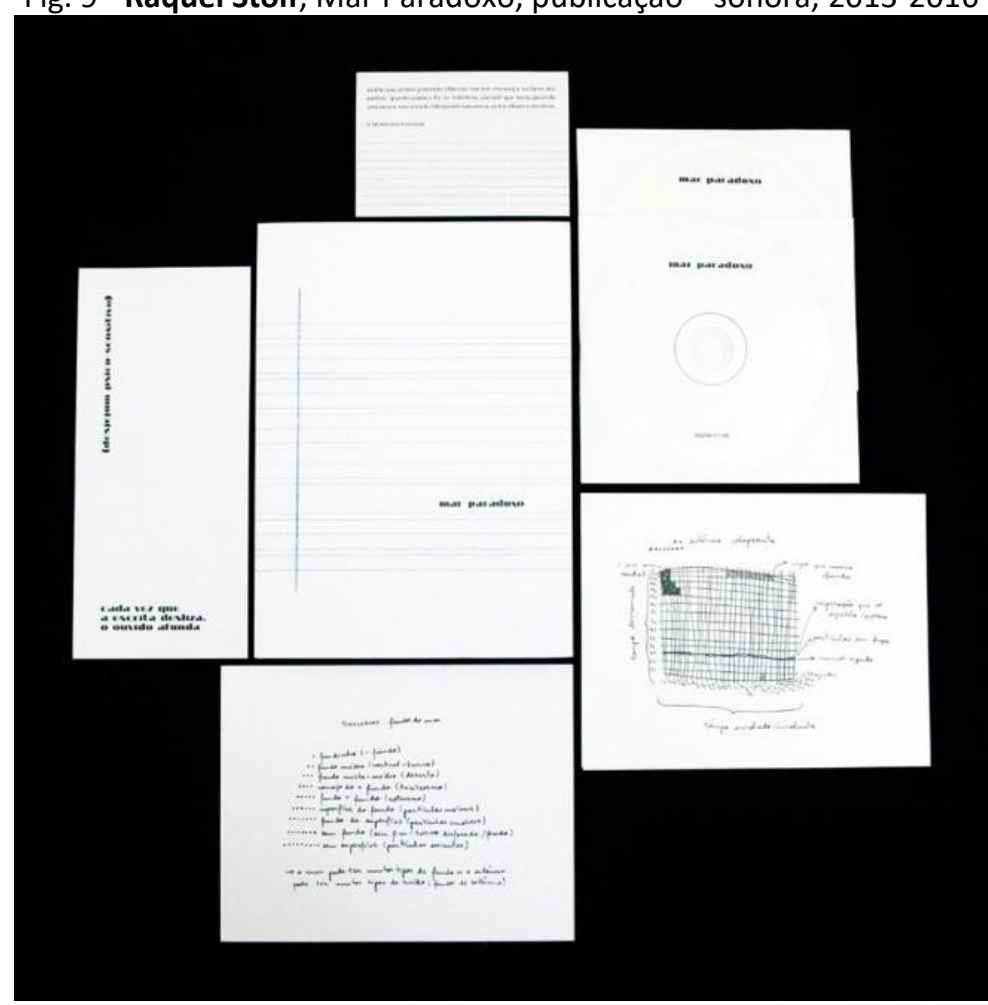

Fonte: Material cedido por Raquel Stolf.

Os dizeres e fazeres das interlocuções aqui realizadas esparramam-se e se misturam na reflexão que atravessa a história da arte da maneira que comentam Coimbra e Grossmann (2001, p.346-347):

produzir arte hoje é operar com vetores de um campo ampliado. Um campo se abre ao entrecruzamento das diversas áreas do conhecimento, num panorama transdisciplinar, sem prejuízo de sua autonomia e especificidade enquanto prática da visualidade.

Além do campo ampliado, o conceito "espaço como prática" de Michel Certeau também pode ser inserido nestas reflexões, pois conforme Stolf (2011, p. 160), nas instalações, "sons, textos e objetos parecem se revezar ou variar, na medida em que são percebidos em durações, velocidades, volumes, planos e alturas diferentes, suscitando uma audição flutuada e uma escuta flutuante". Nesse "espaço como prática" se intercalam e/ou se integram imagens, peças sonoras e textos em descontinuidades provocativas de experiências diversas. Tudo ocupa o espaço e são

\footnotetext{
${ }^{11}$ Os áudios da publicação mar paradoxo estão disponíveis em: https://soundcloud.com/marparadoxo/. Acesso em: 10 set. 2019. O vídeo está disponível em: https://vimeo.com/256401182/. Acesso em: 10 set. 2019.
} 
interdependentes, seja o tempo, o espaço, o lugar, os equipamentos eletrônicos, as imagens projetadas e desenhas, os textos que acompanham as imagens, os objetos, as transparências, a luz, o colorido, o som, os propositores, os visitantes, entre outros.

Nessa ideia de interação, de encontro e intersecção com poéticas líquidas, o silêncio é elemento fundamental, tanto por ser objeto de investigação de Stolf, quanto por ser fenômeno que concatena as produções de Toledo, Caycedo e Martinovsky.

O silêncio como investigação na arte tem suas fontes em Duchamp e Cage, que produziram processos e composições influenciando intensamente as práticas artísticas e literárias sequentes, exemplificadas nos eventos Fluxus, Max Neuhaus com a proposição Listen bem como, teorizações sobre o assunto, como $O$ neutro ${ }^{12}$ de Roland Barthes (2003), As formas do silêncio: no movimento dos sentidos de Eni Puccinelli Orlandi (1997), e Um sopro de vida de Clarice Lispector (1978). Segundo Stolf (2011), com esses desdobramentos, o silêncio foi ganhando contornos, sinônimos, adjetivos, sobrenomes e uma infinidade de significações. Nessa perspectiva,

\begin{abstract}
o silêncio na realidade, não existe. Nunca existe uma ausência de som, que é como os dicionários definem o silêncio. O silêncio é simplesmente...uma questão mental. Uma questão de saber se uma pessoa está escutando os sins que não está provocando. Não sou eu que faço os pássaros cantarem, mas eu os ouço e não estou falando: a isso chamamos de silêncio. O silêncio é um meio de ouvirmos o que nos cerca (CAGE Apud STOLF, 2011, p. 225).
\end{abstract}

À sua maneira, os propositores de arte contemporânea aqui correlacionados procuraram meios para escutar o entorno e através das suas produções provocar/conduzir/convidar a fazer o mesmo. O que interferiu na pausa para ouvir o entorno? Quais silêncios podem ser ouvidos? Como poderiam ser registrados? Como escutar o silêncio como imanência, como possível estado, sendo sempre relacional e situacional? Há um repertório inesgotável para ser explorado no campo educacional em obras potentes quanto estas aqui comentadas.

Se uma coisa é o que se ouve e a outra é o que se vê, talvez uma caracterização possível estaria na escuta com suas espessuras e na visualidade com seus "regimes escópicos"13 ou seja: o visual, o visível e a visão, conforme destacado por Ulpiano Meneses:

a) O visual, que engloba a "iconosfera" e os sistemas de comunicação visual, os ambientes visuais, a produção /circulação/consumo/ação dos recursos e produtos visuais, as instituições visuais, etc.;

\footnotetext{
12 Refere-se às anotações das aulas do curso O neutro, ministrado por Barthes no primeiro semestre de 1978 no Collège de France (STOLF, 2011).

13 “Expressão cunhada por Christian Metz" (MENESES, 2003, p. 47). 
b) O visível, que diz respeito à esfera do poder, aos sistemas de controle, à "ditadura do olho" ao ver/ser visto e ao dar-se/não-se-dar a ver, aos objetos de observação e às prescrições sociais e culturais de ostentação e invisibilidade, etc.;

c) A visão, os instrumentos e técnicas de observação, os papeis do observador, os modelos e modalidades do "olhar" (2005, p. 46-47)

Nesse caso, trata-se de pensar também sobre a imagem de arte contemporânea no campo da visualidade como discurso, um enunciado que diz o que diz à sua maneira de presença/ausência, que atravessa lugares interpondo-se no tempo, o tempo todo. O modo e os meandros pelos quais uma imagem é construída podem transbordar algo mais, produzindo atravessamentos entre o que se tem para mostrar e modo como se mostra. Portanto, não é uma questão de categorizar, o que é isso ou aquilo, nem de isolar a visualidade da escuta, mas é uma reflexão que decorre da possibilidade de pensar pedagogicamente um trabalho com as imagens em fluxo; até porque talvez seja por meio delas uma (única) forma de acesso à arte contemporânea. Assim, a escuta e o olhar afundam para um estranho mundo profundo, turvo, desconhecido, impreciso. Quais sentidos podem emergir? Quais interações provocam?

Diversos são os aspectos envolvidos na poética contemporânea, poderia se tratar da multiplicidade, das subversões, dos deslocamentos, das apropriações, das contaminações, da desordem, pois tudo isso são descontinuidades e continuidades e ao existirem, consistem na montagem de vários fragmentos, de tal forma que

\footnotetext{
o artista contemporâneo é um operador da visualidade e seu trabalho, uma intervenção no campo da cultura: é na atuação de uma inteligência plástica potencializada ao máximo que o artista busca eficiência em sua prática, agora estruturada na forma de um Projeto Plástico, sob o signo da Transdisciplinaridade (cruzamento e superposição de vários campos do conhecimento) e Intermídia (livre trânsito entre diferentes meios de expressão, com utilização de diversos materiais) (COIMBRA; GROSSMANN, 2001, p. 349).
}

Discutir a produção de arte contemporânea é aventurar-se nas correntezas dos experimentos e processos, nos conceitos e atitudes, no tempo espaço e lugar, nas formas intersomáticas de aprendizagem e transdisciplinares da ação educativa. É abordar a realidade e flexibilizar as bases conceituais, históricas, culturais e sociais. E ainda é uma discussão ética da liberdade, em prol da educação, pois abrem-se para debates, experiências, possibilidades e sentidos. 
A fluidez que interliga os propositores relacionados perpassa a poética líquida e os processos artísticos contemporâneos, para confluir na possibilidade de alargar ou aprofundar questões no âmbito da educação e no ensino de arte. A Gente Rio, constituída da expedição às margens dos rios e da escuta das histórias dos ribeiros, assinala a crítica à ação exploratória do ambiente e a nulidade das condições humanas decorrentes desse movimento. RIVER FILM, remete à passagem da vida, por suas vias ou por suas veias, reafirmando o mistério daquilo que transcorre normalmente de um local ao outro, sendo o que é, em seu puro estado de rio. Com o manuseio das ampulhetas Glu-Glu expandem-se sensações lúdicas e movimentos delicados proporcionados pela leveza e transparência dos materiais; efeitos que podem ser explorados em experiências com bolhas de sabão. $\mathrm{Na}$ investigação de Mar Paradoxo, a propositora realizou uma pesquisa poética combinatória entre a escrita e a escuta, o ruído e o silêncio; estes que podem vir a ser argumentos propositivos para ouvir e compor partituras de outros cotidianos, lugares e espaços.

\section{ASPECTOS DA ARTE CONTEMPORÂNEA NA EDUCAÇÃO}

A fusão entre a arte e a vida provocam questionamentos quanto à própria arte e a interação do público com ela. Proposições contemporâneas e estranhamentos são polos de incompreensões e discussões que repercutem suas vozes na educação escolar. Favaretto (2010, p. 225), ao abordar essas relações, salienta a necessidade de se planejar o ensino de arte a partir da contemporaneidade, destacando que "o essencial é o acesso à experiência estética a partir do contato e do trabalho dos artistas". Não há conhecimento de arte sem arte, afirmação adequada para todos os níveis de ensino, propondo a supressão de algumas metodologias determinadas por pensamentos voltados à competência e ao resultado. A questão tem provocado debates nos quais se volta a atenção para o ensino da arte contemporânea e suas reverberações, o que igualmente é destacado no texto de Favaretto (2010, p. 227), onde afirmou que "existe um problema, uma inquietação e alguma confusão sobre a composição ou intersecção dos dois termos da equação, educação e arte". Nesse caso, persiste a discussão e a necessidade de colocar em pauta a arte no contexto educacional, pensada em termos conceituais e de práticas que suportam essa relação, estendendo aí, para além das características, a problematização da própria ideia do que significa a formação estética. 
A perspectiva colocada por Favaretto (2010), é de que a arte contemporânea na educação possa não somente ser entendida à guisa de algo a ser construído, mas também de algo em processo de destituição, de deposição, de deslocamento, de irrupções - do que é conhecido, do que é entendido e da subjetividade socialmente, economicamente, ciberneticamente criada. Não se trata da compreensão, nem mesmo de formação sobre a arte contemporânea, mas o que o autor propõe, com base em Deleuze, é "o valor disruptivo da arte na educação, em que o aprendizado surge pelo espírito de investigação, pela interpretação dos signos da experiência" (FAVARETTO, 2010, p. 232). Assim pensando, a experiência com a arte contemporânea na educação, não se limita ao discurso da criatividade, pois neste implica a originalidade e a inventividade, ambas categorias da modernidade artística, bem como avança a expectativa do desenvolvimento da sensibilidade, um posicionamento regulado pela falsa divisão entre o inteligível e o sensível, pois ambas as dimensões são humanas, portanto, indissociáveis. E ainda, não se molda aos discursos educacionais focados em competências e habilidades, que são os "verdadeiros postulados subjacentes ao ensino de arte" (FAVARETTO, 2010, p. 243).

O propósito de repensar a arte contemporânea na educação surge da seguinte questão:

como fazer com que os acontecimentos de linguagem, sensações, percepções e afetos, que se fazem nas palavras, nas cores, nos sons, nas coisas, nos lugares e eventos sejam articulados como dispositivos, como agenciamentos sentidos irredutíveis ao conceitual, como outro modo de experiência e do saber? (FAVARETTO, 2010, p. 233).

Em não havendo uma resposta, mas tantas quantas surgirem à medida que existem experimentações pedagógicas, pode-se no mínimo sustentar que um requisito indispensável na proposição da arte atual na educação é o de praticar a si próprio enquanto aquele que ensina e vivencia a experiência da arte. Na possibilidade simultânea entre o praticante, o pensador e o mediador, parece constituir-se um lugar para o exercício de tal tarefa no ensino de arte, podendo ser referenciado a partir de concepções e ações disponíveis nos projetos ou programas educativos de exposições, museus ou bienais, exemplificando as ações educativas nas bienais do Mercosul. Segundo Mônica Hoff (2011), os estudos no setor educativo da Bienal em Porto Alegre englobam preocupações, reflexões e práticas sobre o enigmático campo da arte contemporânea e a relação do público com ela, questões essas também centrais em diversos museus e instituições culturais em todo o mundo. 
Igualmente ao que se passa nos espaços culturais, pode-se pensar sobre o acesso à arte contemporânea na educação e as reações de estudantes nesse contato, pois que sentidos decorrem dessas experiências? Quais reflexões emergem? O que se pode apreender, sentir e viver com a arte na contemporaneidade, na educação? A arte atual está inserida nos projetos pedagógicos e currículos escolares? É um projeto contínuo e permanente ou refere-se a situações ocasionais?

Diante de tamanha prontidão que o mundo comunicacional decorrente da tecnologia nos trouxe, que se reflete particularmente nos desafios que a arte contemporânea apresenta, a situação pode ser revertida de modo a trazer mudanças que beneficiem a educação, provocando alterações nos modos de ver, ouvir, sentir, perceber, dialogar, interpretar, experimentar, tal qual as poéticas líquidas dos propositores aqui estudados. De que modo produções como essas podem instigar o pensamento sobre a educação? O que pode advir dessas discussões são inúmeras possibilidades, mas de imediato, pressupõem "um descaminho daquilo que é conhecido" (FAVARETTO, 2010, p. 232).

\section{CONFLUÊNCIAS}

O estado movediço que atraiu Carolina Caycedo e Helder Martinovsky para o rio, Amelia Toledo e Raquel Stolf para o mar, permitem, dentre outras possibilidades, enriquecer as abordagens sobre a arte por meio de discursos informes e assonantes, compreendidos aqui como um meio, uma alternativa, um lugar-entre, uma investigação ou uma experiência da arte com o vivido. Escutar com os olhos, ver com os ouvidos, escutar e ver com o corpo são situações-processos que divergem de um estado previsível-passível-espectador, por isso, supõem-se que as oscilações e alterações pressupostas na arte contemporânea também sejam experimentações vividas no ensino de arte e na educação.

A convocação transborda das ações educativas nos espaços culturais para ações pedagógicas com a arte contemporânea em quaisquer espaços, e os desafios que isso impõe, considerando-se o mundo cibernético da comunicação em que se vive, e em confronto direto com as atuais reformas educacionais brasileiras, por privilegiarem o desenvolvimento de habilidades e competências. $\mathrm{Na}$ contramão, a arte atual potencializa o vivido, os acontecimentos, as sensações, percepções e os afetos que se fazem em escutas, visualidades e corpos-sentidos que se realizam e se atualizam em processo e na troca das experiências. 
Ao confluir os termos contextualizados, arte contemporânea e educação, observa-se a complexidade diante dos desafios de ambos os lados; daí a importância de se investigar como se dão essas relações, uma vez que mesmo sendo únicas - pois em uma mesma exposição, estudantes da mesma faixa etária e condições socioculturais semelhantes provavelmente terão reações diferentes - mas podem-se identificar tendências, aspectos a sanar metodologicamente e traçar estratégias. É imprescindível que os/as professores/as estejam familiarizados/as tanto com os paradoxos sociais e políticos que se vive, quanto com o papel da arte contemporânea neste contexto, por se encontrar muito mais próximo da vida cotidiana do que pode parecer.

Sendo assim, o diálogo entre estes propositores de arte contemporânea, seus processos de investigação e as produções exemplificadas, consiste numa reflexão que se desdobra ou flui, como a água em seus diferentes estados físicos e características - o que converge com a educação e o ensino de arte - onde evocar o silêncio pode ser uma maneira de estar atento/atenta às sutilezas desse tempo.

\section{REFERÊNCIAS}

ARCHER, Michael. Arte Contemporânea: uma história concisa. São Paulo: Martins Fontes, 2001.

CAYCEDO, C. A fome como professora, São Paulo, 2016. Website DOCPLAYER https://docplayer.com.br/56895212-A-fome-como-professora.html. Acesso em: 29 set. 2019.

CAYCEDO, C. River Books / Libros Río, São Paulo, 2016. Website Carolina Caycedo. Disponível em: http://carolinacaycedo.com/river-books-libros-rio/ Acesso em: 29 set. 2019.

CAUQUELIN, A. Arte Contemporânea: uma introdução. São Paulo: Martins Fontes, 2005.

FAVARETTO, C. F. Arte Contemporânea e educação. Revista Ibero-americana de Educação, v. 53, p. 225-235, 1 maio 2010. DOI: https://doi.org/10.35362/rie530568. Disponível em: https://rieoei.org/historico/documentos/rie53a10.pdf/ Acesso em: 28 fev. 2020.

GROSSMANN, M. Arte contemporânea brasileira: à procura de um contexto. In: BASBAUM, R. (Org.). Arte Contemporânea brasileira: texturas, diç̧ões, ficções, estratégias. Rio de Janeiro: Rios Ambiciosos, 2001.

HOFF, M. Curadoria pedagógica, metodologias artísticas, formação e permanência: a virada educativa da Bienal do Mercosul. In: HELGUERA, P.; HOFF, M. (Org.). Pedagogia no campo expandido. Porto Alegre: Fundação Bienal de Artes Visuais do Mercosul, 2011. Disponível em: 
https://docplayer.com.br/41967916-Pedagogia-no-campo-expandido-org-pablo-helguera-emonica-hoff.html. Acesso em: 01 fev. 2019.

LANDOWSKI, Eric. Interações Arriscadas. São Paulo: Estação das Letras e Cores, 2014.

MENESES, U. T. B. de. Fontes visuais, cultura visual, História visual. Balanço provisório, propostas cautelares. Revista Brasileira de História, São Paulo, v. 23, n. 45, p.11-36, 2003.

NAME, D.; COSTA, M. de L. Catálogo da exposição Amélia Toledo: forma fluida. Paço Imperial Rio de Janeiro: ADUPLA, 2015.

RADUNZ, Dennis. Textos/Interlocuções de RIVER FILM/pedra-fantasma/mar paradoxo. In: Martinovsky, H; Stolf, R. (org.). Exposição RIVER FILM / pedra-fantasma / mar paradoxo. Florianópolis: Museu da Imagem e do Som de Santa Catarina, 2017. Disponível em: http://www.cultura.sc.gov.br/downloads/mis/downloads-4/2200-river-film-denis-raduenz/file. Acesso em: 27 fev. 2020.

RUCH, Michael. Novas mídias na arte contemporânea. São Paulo: Martins Fontes, 2006.

STOLF, Raquel. Entre a palavra pênsil e a escuta porosa: [investigações sob proposições sonoras]. 2011. Tese (Doutorado em Artes Visuais) - Programa de Pós-Graduação em Artes Visuais, Universidade Federal do Rio Grande do Sul, Porto Alegre, 2011. Disponível em: https://lume.ufrgs.br/handle/10183/34774. Acesso em: 21 set. 2019

STOLF, Raquel. Sob/sobre notas-desenhos de escuta. Arteriais. Revista do Programa de PósGraduação em Artes, Belém, PA, v. 3, n. 4, 20 p. 108-116, 2017. DOI: http://dx.doi.org/10.18542/arteriais.v3i4.4869. Disponível em: https://periodicos.ufpa.br/index.php/ppgartes/article/view/4869. Acesso em: 30 fev. 2020.

ZIMMER. Claudia. Diário de viagem: uma excursão em cinco tempos. Textos/Interlocuções de RIVER FILM/pedra-fantasma/mar paradoxo. In: Martinovsky, H; Stolf, R. (org.). Exposição RIVER FILM / pedra-fantasma / mar paradoxo. Florianópolis: Museu da Imagem e do Som de Santa Catarina, 2017. Disponível em http://www.cultura.sc.gov.br/downloads/mis/downloads-4/2199-diario-deviagem-uma-excursao-em-cinco-tempos-claudia-zimmer-1/file. Acesso em: 27 fev. 2020.

ZUKER, Fábio. Carolina Caycedo. In: CATÁLOGO 32a Bienal de São Paulo: incerteza viva, São Paulo: Fundação Bienal de São Paulo, 7 set.-11 dez., 2016. p. 117. Disponível em: http://www.bienal.org.br/publicacoes/8077. Acesso em: 29 set. 2019. 